\title{
Volumetric Magnetic Resonance Imaging Study of Brain and Cerebellum in Children with Cerebral Palsy
}

\author{
Piotr Kułak, ${ }^{1}$ Elżbieta Maciorkowska, ${ }^{2}$ and Elżbieta Gościk ${ }^{1}$ \\ ${ }^{1}$ Department of Pediatric Radiology, Medical University of Bialystok, 15-274 Białystok, Poland \\ ${ }^{2}$ Department of Developmental Age Medicine and Pediatric Nursing, Medical University of Białystok, 15-296 Białystok, Poland
}

Correspondence should be addressed to Piotr Kułak; piotrku@gmail.com

Received 2 January 2016; Revised 8 June 2016; Accepted 3 July 2016

Academic Editor: Jinyuan Zhou

Copyright () 2016 Piotr Kułak et al. This is an open access article distributed under the Creative Commons Attribution License, which permits unrestricted use, distribution, and reproduction in any medium, provided the original work is properly cited.

\begin{abstract}
Introduction. Quantitative magnetic resonance imaging (MRI) studies are rarely used in the diagnosis of patients with cerebral palsy. The aim of present study was to assess the relationships between the volumetric MRI and clinical findings in children with cerebral palsy compared to control subjects. Materials and Methods. Eighty-two children with cerebral palsy and 90 age- and sexmatched healthy controls were collected. Results. The dominant changes identified on MRI scans in children with cerebral palsy were periventricular leukomalacia (42\%) and posthemorrhagic hydrocephalus (21\%). The total brain and cerebellum volumes in children with cerebral palsy were significantly reduced in comparison to controls. Significant grey matter volume reduction was found in the total brain in children with cerebral palsy compared with the control subjects. Positive correlations between the age of the children of both groups and the grey matter volumes in the total brain were found. Negative relationship between width of third ventricle and speech development was found in the patients. Positive correlations were noted between the ventricles enlargement and motor dysfunction and mental retardation in children with cerebral palsy. Conclusions. By using the voxel-based morphometry, the total brain, cerebellum, and grey matter volumes were significantly reduced in children with cerebral palsy.
\end{abstract}

\section{Introduction}

Advances in neuroimaging provide unique opportunities to evaluate brain structure, biochemistry, and function [1].

Parents and clinicians concerned about high-risk infants and children with motor delay or cerebral palsy seek information on cause, treatment, and prognosis. Used in combination with history and examination, neuroimaging studies can improve diagnosis and management. In children with cerebral palsy syndromes including spastic diplegia, quadriplegia, hemiplegia, and extrapyramidal movement disorders, conventional magnetic resonance imaging (MRI) has become an important determinant of diagnosis, management, and prognosis [2]. Conventional MRI reveals anatomical features of the brain and is typically used to quantify brain tissue volume and shape.

Currently, it is now widely accepted that most cerebral palsy is not the result of intrapartum hypoxia $[3,4]$. Lesions responsible for periventricular leukomalacia and posthemorrhagic porencephaly are considered to occur early in the third trimester. Both vascular and intrinsic metabolic factors are thought to be responsible for the localization of periventricular leukomalacia. In patients with cerebral palsy, congenital abnormalities are often found in MRI $[5,6]$.

Ventricular enlargement is common in preterm and lowbirth-weight infants. Furthermore, ventricular enlargement on cranial ultrasound in children was found to be significant risk factor for cerebral palsy [7]. Enlargement of the ventricles may occur for a number of reasons, such as loss of brain volume (infection, hypoxia, and infarction) or impaired outflow or absorption of cerebrospinal fluid from the ventricles.

It was also demonstrated that ventricular dilatation increases the risk of poor development of children born at term. And Evans' index (ventricular-brain ratio) above 0.35 is a sensitive measure of developmental impairment [8].

Conventional MRI is currently recommended as a standard evaluation in children with cerebral palsy where the aetiology has not been established $[9,10]$. However, quantitative MRI studies are rarely used in the diagnosis of patients with cerebral palsy [11, 12]. Voxel-based morphometry (VBM) as 
an automated technique is more sensitive than conventional MRI in investigating the structural changes of the whole brain [11]. The recent MRI studies have employed VBM to detect regional grey matter and white matter volume abnormalities in children with cerebral palsy $[13,14]$.

However, previous studies mainly focused on patients with cerebral palsy who exhibited abnormal findings in conventional MR particularly in white matter changes [15-17]. Until now, only few studies have investigated grey matter changes in the brain in children with cerebral palsy [18].

The first objective was to detect grey matter changes in the brain in children with cerebral palsy using the VBM technique. The second one was to investigate the relationships between the volumetric MRI and clinical findings in children with cerebral palsy.

\section{Materials and Methods}

2.1. Study Design. We retrospectively evaluated MRI findings and medical data of children with cerebral palsy referred to Department of Pediatric Radiology in Białystok, Poland, from imaging studies from January 2006 to December 2012. All children with cerebral palsy and control children were born to mothers living in the Podlaskie region.

2.2. Subjects. The present study included 82 children with cerebral palsy. Of these children, 30 had spastic diplegia, 27 had spastic tetraplegia, and 25 had spastic hemiplegia. A group of 96 healthy right-handed children matched for age and gender were recruited as a comparison group. All subjects were free from neurological or psychiatric diseases, they had normal intellectual development, and their brain MRI scans were normal. Children with postnatal meningitis, encephalitis, trauma, intra-axial or extra-axial tumors other than small prechiasmatic and chiasmatic optic nerve gliomas, and metabolic or degenerative disorders were excluded from the study.

2.3. Motor Function. Each child was classified according to the Gross Motor Function Classification System (GMFCS) [19].

2.4. Mental Development. All the children in this group had 1 or more formal psychological assessments (the typical Wechsler Intelligence Scale for Children, Polish version). Mental development was divided into small delay, 70 to 84 IQ; moderate delay, 50 to 69 IQ; and severe delay, <50 IQ. Normal children have an IQ > 90. All 96 healthy subjects had normal intelligence.

2.5. MRI. All MRI scans were obtained using a 0.35-T MR scanner (Siemens, Germany) with the use of a standard circular polarized head coil. The images were assessed by a neuroradiologist (Elżbieta Gościk). A set of sagittal T1-weighted images were acquired with the following scan parameters: a time repetition (TR) of $20 \mathrm{~ms}$, a time echo (TE) of $8.9 \mathrm{~ms}$, and a flip angle of $45^{\circ}$. Each volume consisted of between 124 and 128 sagittal slices, and each slice had dimensions of $256 \times 256$ pixels. Voxel's dimensions were $0.9 \times 0.9 \times 5 \mathrm{~mm}$. Routinely, brain data sets were saved and stored in a standard DICOM format controlled by a Kodak Direct View OSM (Eastman Kodak Company, USA) storing system. For postacquisition processing of MR images, the DICOM files were transferred into a Windows controlled desktop PC, where they were processed using specialized image data processing software.

2.6. Image Analysis. Analyze 11 Biomedical Imaging Software (AnalyzeDirect, Overland Park, KS, USA) was used to estimate the total grey matter of the brain and the brain and cerebellum volumes of each subject. The collected original MRI DICOM volumetric data were then converted to internal volumetric AVW format. When analyzing the images, Analyze 11 uses a variety of volume rendering algorithms, including volumetric compositing, depth shading, shading colors, maximal intensity shade of grey, the entire volume, and particular volume voxels per pixel in the image DICOM. Voxel (volumetric element) is three-dimensional graphics smallest element of space, in a sense equivalent to two-dimensional pixel graphics. Using a voxel image shows a three-dimensional array as, for example, $512 \times 512 \times 512$ voxels. This software also allows image display at three levels, that is, transverse, frontal, and sagittal view of the volume (Figure 1).

Prior to voxel-based morphometry preprocessing, nonbrain tissues surrounding the entire brain in each image were manually removed using the Analyze 11 software to maximize sensitivity in data analysis [20]. The global volumes of grey matter, white matter, and cerebrospinal fluid for each scan were calculated from the maps of the raw (nonnormalized) MRI. The volume of each tissue class was estimated as the total number of voxels multiplied by the voxel size. Wholebrain tissue volume was calculated by summing the grey matter, white matter, and cerebrospinal fluid volumes for each subject. However, in this study, we presented only data of the total brain, cerebellum, and the grey matter volumes. We did not analyze the white matter volumes.

2.7. Definitions. Cerebral palsy was defined as a group of disorders of the development of movement and posture, causing activity limitation, that are attributed to nonprogressive disturbances that occurred in the developing fetal or infant brain [21]. Cerebral palsy was classified as spastic tetraplegia (spasticity of all four limbs and of about equal involvement) and spastic diplegia (spasticity of lower limbs more pronounced than upper limbs). Hemiplegic cerebral palsy refers to one arm and one leg affected on either the right or left side of the body. Epilepsy was defined as a separate occurrence of two or more apparently unprovoked seizures. Prematurity was defined by the World Health Organization as an infant with a gestation of less than 37 weeks from the first day of the last menstrual period. Asphyxia is defined as an Apgar score $\leq 4$.

2.8. Statistical Analysis. Descriptive statistics were used to examine each study variable individually. The differences between the groups were determined by the parametric $t$-test and nonparametric statistical tests: Wilcoxon signed-rank test and Chi-square test where appropriate. Linear regression was used to measure the dependence regarding age, gender, 
Apgar score, mental retardation, and Gross Motor Function Classification System of cerebral palsy and grey matter volume. All $P$ values were two-tailed. Statistical significance was defined as $P<0.05$. Statistics were calculated using Statistica 10.0 .

2.9. Ethics. The study was approved by the ethics committee of the Medical University of Białystok, Poland (number RI-002/244/2009). Consent was not obtained from parents of children. Patient records were anonymized and deidentified prior to analysis.

\section{Results}

In total, 52 boys and 30 girls, with age range of 3-17 years, mean age of $10.9 \pm 6.9$ years, and cerebral palsy on MRI, were included. More than half of the children (48) were born at term and 34 were born preterm. Thirty patients experienced birth asphyxia ( $\leq 4$ Apgar score). In the control group, 47 girls and 43 boys, with age range of 1-18 years and mean age of $12.4 \pm 4.3$ years, on MRI were included. The proportions of males and females between the groups did not differ significantly. Details are shown in Table 1.

3.1. MRI Findings. This study's sample of 82 patients with cerebral palsy showed a high rate $(80 \%)$ of positive findings. In our study, 19 patients (20\%) had normal MRIs. The dominant changes identified on MRI scans in children with cerebral palsy were periventricular leukomalacia (PVL) (42.4\%), posthemorrhagic hydrocephalus $(20.7 \%)$, and ventriculomegaly of lateral ventricles $(9.7 \%)$. These changes were found in 60 patients with cerebral palsy. In other cases, corticalsubcortical atrophy (9.7\%), porencephaly (6.5\%), DandyWalker syndrome $(2.2 \%)$, and corpus callosum hypoplasia $(2.2 \%)$ were found. In single cases, corpus callosum agenesis, schizencephaly, and pachygyria were noted. All porencephaly cases were observed in patients with spastic hemiplegia.

All cortical-subcortical atrophy and congenital brain malformations were noted in patients with spastic tetraplegia. Sixteen patients with cerebral palsy had normal MRI scan results. Normal MRI results were found in patients with spastic diplegia.

3.2. Volumetric MRI Findings. The total grey matter volume of the brain was significantly $(P<0.028)$ reduced in the patient group compared with controls. Details are shown in Table 2.

The total brain and cerebellum volumes were significantly $(P<0.001)$ reduced in children with cerebral palsy compared to the control subjects. The lateral ventricles and thirdventricle widths were significantly $(P<0.001)$ larger in children with cerebral palsy compared to controls (Table 2).

Significant difference $(P<0.001)$ was found in Evans' index between children with cerebral palsy $(0.34 \pm 0.23)$ and the control group $(0.27 \pm 0.21)$.

3.3. MRI Correlations. Linear regression demonstrated a positive relationship $(r=0.265 ; P=0.011)$ between the total brain volume and the age in children with cerebral palsy
TABLE 1: Clinical data of children cerebral palsy and controls.

\begin{tabular}{|c|c|c|c|}
\hline Data & $\begin{array}{c}\text { Cerebral } \\
\text { palsy } \\
(n=82)\end{array}$ & $\begin{array}{l}\text { Controls } \\
(n=90)\end{array}$ & $P$ value \\
\hline $\begin{array}{l}\text { Age, y (range, } \\
7-15)\end{array}$ & $10.9 \pm 6.9$ & $12.4 \pm 4.3$ & NS \\
\hline \multicolumn{4}{|l|}{ Gender } \\
\hline Male & 52 & 43 & NS \\
\hline Female & 30 & 47 & NS \\
\hline Vaginal birth & 61 & 68 & NS \\
\hline Cesarean birth & 21 & 24 & NS \\
\hline Gestation, wk & $35.9 \pm 4.2$ & $39.2 \pm 1.2$ & $<0.001$ \\
\hline \multicolumn{4}{|l|}{ Delivery } \\
\hline Term & 48 & 85 & NS \\
\hline $\begin{array}{l}\text { Preterm } \\
<37 \mathrm{wk}\end{array}$ & 34 & 5 & $<0.001$ \\
\hline $\begin{array}{l}\text { Apgar score } \\
(1-10)\end{array}$ & $5.9 \pm 3.3$ & $9.1 \pm 1.5$ & $<0.001$ \\
\hline Asphyxia & 30 & 1 & $<0.001$ \\
\hline Birth weight, $g$ & $2615.8 \pm 935.1$ & $3343.2 \pm 497.6$ & $<0.001$ \\
\hline $\begin{array}{l}\text { Low birth } \\
\text { weight } \\
(<2500 \mathrm{~g})\end{array}$ & 22 & 5 & 0.0022 \\
\hline $\begin{array}{l}\text { Normal birth } \\
\text { weight } \\
(>2500 \mathrm{~g})\end{array}$ & 60 & 85 & NS \\
\hline \multicolumn{4}{|l|}{$\mathrm{GMFCS}^{\wedge}$} \\
\hline Level 1 & 0 & 90 & \\
\hline Level 2 & 20 & 0 & \\
\hline Level 3 & 25 & 0 & \\
\hline Level 4 & 24 & 0 & \\
\hline Level 5 & 13 & 0 & \\
\hline \multicolumn{4}{|l|}{$\begin{array}{l}\text { Mental } \\
\text { development }\end{array}$} \\
\hline Normal & 43 & 90 & 0.0098 \\
\hline Small delay & 17 & 0 & $<0.001$ \\
\hline Mild & 12 & 0 & $<0.001$ \\
\hline Severe & 10 & 0 & 0.0032 \\
\hline Epilepsy & 24 & 0 & $<0.001$ \\
\hline
\end{tabular}

Chi-square test; NS: not significant; $\wedge$ : not compared.

(Table 3). Similar correlation $(r=0.289 ; P=0.004)$ was also noted in the control group.

Age of children with cerebral palsy was positively correlated with the total grey matter volume of brain $(r=0.248$; $P=0.016)$. Similar correlation $(r=0.323 ; P=0.001)$ was also found in the control subjects (Table 4 ).

No correlations between the total grey matter volume of brains and gender, Apgar score, birth weight, motor development, mental development, and epilepsy in both groups were noted.

No significant correlations between the total cerebellum volume and the tested variables in both groups were found. Details are not shown. 
TABLE 2: Mean values of the total grey matter volume of brain, brain volume, cerebellum volume, and the widths of the lateral ventricles and third ventricle in children with cerebral palsy $(n=82)$ and the control group $(n=90)$.

\begin{tabular}{|c|c|c|c|c|c|}
\hline Variable & Mean & Min. & Max. & $\mathrm{SD}$ & $P$ value \\
\hline \multicolumn{6}{|c|}{ Total grey matter volume of brain $\left(\mathrm{mm}^{3}\right)$} \\
\hline Cerebral palsy & $8,986.31$ & 320.18 & $1,9458.62$ & $5,283.03$ & \multirow{2}{*}{0.028} \\
\hline Control & $10,803.78$ & 593.10 & $1,8954.58$ & $5,492.06$ & \\
\hline \multicolumn{6}{|c|}{ Total brain volume $\left(\mathrm{mm}^{3}\right)$} \\
\hline Cerebral palsy & $1,1943.38$ & $1,911.83$ & $2,1612.53$ & $5,649.39$ & \multirow{2}{*}{$<0.001$} \\
\hline Control & $14,800.77$ & $3,314.16$ & $2,3411.76$ & $5,611.59$ & \\
\hline \multicolumn{6}{|c|}{ Total cerebellum volume $\left(\mathrm{mm}^{3}\right)$} \\
\hline Cerebral palsy & 919.65 & 554.37 & $1,721.19$ & 214.10 & \multirow{2}{*}{$<0.001$} \\
\hline Control & $1,426.54$ & 748.51 & $2,506.12$ & 349.84 & \\
\hline \multicolumn{6}{|c|}{ The lateral ventricles width $(\mathrm{mm})$} \\
\hline Cerebral palsy & 37.58 & 25.93 & 81,31 & 9.29 & \multirow[t]{2}{*}{$<0.001$} \\
\hline Control & 33.68 & 28.29 & 40,51 & 2.41 & \\
\hline \multicolumn{6}{|c|}{ Third-ventricle width (mm) } \\
\hline Cerebral palsy & 5.26 & 1.78 & 17.46 & 3.25 & \multirow{2}{*}{$<0.001$} \\
\hline Control & 2.59 & 1.52 & 5.97 & 0.93 & \\
\hline
\end{tabular}

Wilcoxon signed-rank test.

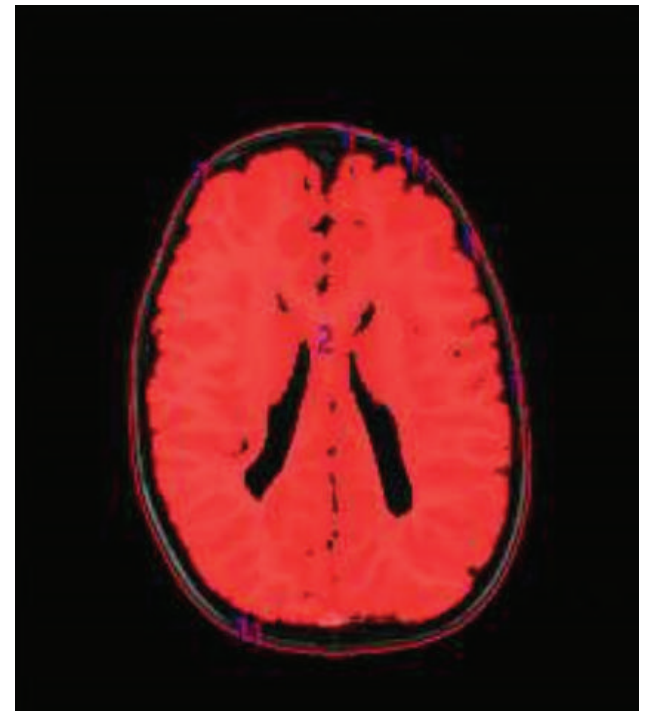

(a)

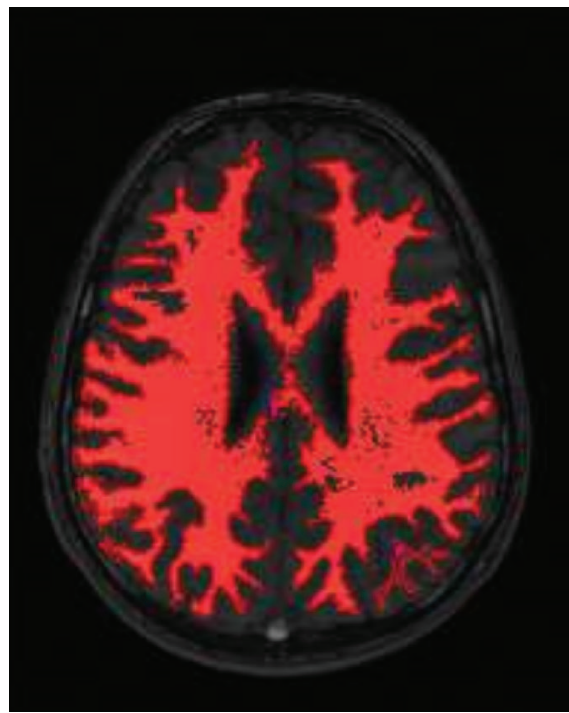

(b)

Figure 1: (a) An image of whole brain by the program Analyze 11 (own source). (b) An image of the white matter of brain by the program Analyze 11 (own source).

Significant correlation $(r=0.205 ; P=0.049)$ between the width of lateral ventricles and GMFCS and mental retardation in children with cerebral palsy was found (Table 5).

No significant correlations between the width of lateral ventricles and the tested variables in the control group were found.

Negative correlation $(r=-0.780 ; P=0.0002)$ between third-ventricle width and speech development in children with cerebral palsy was found. A positive relationship $(r=$ 0.221; $P=0.033$ ) between third-ventricle width and mental retardation was found. Data are shown in Table 6.

\section{Discussion}

We demonstrated significant abnormalities with MRI in $80 \%$ of children with cerebral palsy. The dominant changes identified on MRI scans of patients were PVL. Our findings are comparable with the results of previous reports $[4,6,22-$ 24].

In the current study, we found significant grey matter volume reduction (the total grey matter volume of the brain and cerebellum) in children with cerebral palsy compared to controls. The grey matter volume reductions in the cerebral 
TABLE 3: Correlations between total brain volume and age, gender, gestational age, Apgar score, birth weight, GMFCS, motor and speech development, mental retardation, and epilepsy in children with cerebral palsy $(n=82)$ and controls $(n=90)$.

\begin{tabular}{|c|c|c|}
\hline Variable & $r$ value & $P$ value \\
\hline \multicolumn{3}{|l|}{ Total brain volume versus age } \\
\hline Cerebral palsy & 0.265 & 0.011 \\
\hline Control & 0.289 & 0.004 \\
\hline \multicolumn{3}{|l|}{ Total brain volume versus male sex } \\
\hline Cerebral palsy & -0.085 & \multirow{2}{*}{ NS } \\
\hline Control & -0.091 & \\
\hline \multicolumn{3}{|l|}{ Total brain volume versus female sex } \\
\hline Cerebral palsy & -0.037 & \multirow{2}{*}{ NS } \\
\hline Control & -0.081 & \\
\hline \multicolumn{3}{|l|}{ Total brain volume versus gestational age } \\
\hline Cerebral palsy & 0.100 & \multirow{2}{*}{ NS } \\
\hline Control & 0.085 & \\
\hline \multicolumn{3}{|l|}{ Total brain volume versus Apgar score } \\
\hline Cerebral palsy & 0.1106 & \multirow{2}{*}{ NS } \\
\hline Control & 0.0486 & \\
\hline \multicolumn{3}{|l|}{ Total brain volume versus birth weight } \\
\hline Cerebral palsy & 0.125 & \multirow{2}{*}{ NS } \\
\hline Control & -0.011 & \\
\hline \multicolumn{3}{|l|}{ Total brain volume versus GMFCS } \\
\hline Cerebral palsy & 0.0576 & \multirow{2}{*}{ NS } \\
\hline Control & $\wedge$ & \\
\hline Total brain volume versus siting & & NS \\
\hline Cerebral palsy & 0.1477 & \\
\hline Control & -0.123 & \\
\hline Total brain volume versus standing & & NS \\
\hline Cerebral palsy & 0.115326 & \\
\hline Control & -0.04719 & \\
\hline Total brain volume versus walking & & NS \\
\hline Cerebral palsy & 0.127084 & \\
\hline Control & -0.10585 & \\
\hline Total brain volume versus speech & & NS \\
\hline Cerebral palsy & 0.150530 & \\
\hline Control & 0.020021 & \\
\hline Total brain volume versus mental retardation & & NS \\
\hline Cerebral palsy & -0.14620 & \\
\hline Control & 0.288966 & \\
\hline Total brain volume versus epilepsy & & NS \\
\hline Cerebral palsy & 0.027474 & \\
\hline Control & 0.017008 & \\
\hline
\end{tabular}

$r$ : Spearman rank sum correlation coefficient; NS: not significant. $\wedge$ : not tested for controls.

palsy patients suggest neuronal degeneration and damage. Our findings are in agreement with those of previous studies $[18,22]$.

The pathogenesis of grey matter lesions in PVL is likely due to the same phenomena implicated in white matter lesions [22]. The pathogenesis of PVL likely involves cerebral ischemia-reperfusion. Moreover, we found a significant
TABLE 4: Correlations between the total grey matter volume of brain and age, gender, gestational age, Apgar score, birth weight, GMFCS, motor and speech development, mental retardation, and epilepsy in children with cerebral palsy $(n=82)$ and controls $(n=90)$.

\begin{tabular}{lcc}
\hline Variable & $r$ value & $P$ value \\
\hline Grey matter volume versus age & & \\
Cerebral palsy & 0.248 & 0.017 \\
Control & 0.323 & 0.001 \\
Grey matter volume versus male sex & & NS \\
$\quad$ Cerebral palsy & 0.013 & \\
$\quad$ Control & 0.057 &
\end{tabular}

Grey matter volume versus female sex

NS

Cerebral palsy $\quad-0.024$

Control 0.048

Grey matter volume versus gestational age $\quad$ NS

Cerebral palsy $\quad-0.023$

Control 0.028

Grey matter volume versus Apgar score NS

Cerebral palsy $\quad 0.044$

Control 0.038

Grey matter volume versus birth weight $\quad$ NS

$\begin{array}{ll}\text { Cerebral palsy } & -0.005 \\ \text { Control } & -0.032\end{array}$

Grey matter volume versus GMFCS

$\begin{array}{lcc}\text { Cerebral palsy } & 0.036 & \text { NS } \\ \text { Control } & \wedge & \end{array}$

Grey matter volume versus siting $\quad$ NS

Cerebral palsy $\quad 0.197$

Control -0.011

Grey matter volume versus standing NS

Cerebral palsy $\quad 0.098$

Control 0.068

Total brain volume versus walking NS

Cerebral palsy $\quad 0.085$

Control $\quad-0.024$

Grey matter volume versus speech development

Cerebral palsy $\quad 0.090$

$\begin{array}{lll}\text { Control } & 0.117 & \text { NS }\end{array}$

Grey matter volume versus mental retardation NS

Cerebral palsy $\quad-0.045$

Control 0.323

Grey matter volume versus epilepsy $\quad$ NS

Cerebral palsy $\quad 0.022$

Control $\quad-0.047$

$r$ : Spearman rank sum correlation coefficient; NS: not significant; $\wedge:$ not tested for controls.

correlation between the width of the lateral ventricles and motor function in the GMFCS scale and mental retardation in children with cerebral palsy.

Typical preterm brain injuries include PVL and posthemorrhagic porencephaly $[4,6,22,23]$. PVL usually occurs between gestational weeks 28 and 34 and is caused by an ischemic process in the watershed zone that exists in the 
TABLE 5: Correlations between the lateral ventricles widths of brain and age, gender, gestational age, Apgar score, birth weight, GMFCS, motor and speech development, mental retardation, and epilepsy in children with cerebral palsy $(n=82)$ and controls $(n=90)$.

\begin{tabular}{lcc}
\hline Variable & $r$ value & $P$ value \\
\hline The lateral ventricles width versus age & & \\
Cerebral palsy & 0.078 & NS \\
Control & 0.579 &
\end{tabular}

The lateral ventricles width versus male sex

Cerebral palsy

0.048

Control

0.078

The lateral ventricles width versus female sex

Cerebral palsy

0.060

Control

The lateral ventricles width versus

gestational age

Cerebral palsy

0.067

Control

The lateral ventricles width versus Apgar score

Cerebral palsy

Control

The lateral ventricles width versus birth weight

Cerebral palsy

Control

The lateral ventricles width versus GMFCS

$$
\text { Cerebral palsy }
$$

0.314

Control

The lateral ventricles width versus siting

Cerebral palsy

Control

The lateral ventricles width versus standing

$$
\text { Cerebral palsy }
$$

Control

The lateral ventricles width versus walking

$$
\text { Cerebral palsy }
$$

Control

The lateral ventricles width versus speech development

$$
\begin{aligned}
& \text { Cerebral palsy } \\
& \text { Control }
\end{aligned}
$$

The lateral ventricles width versus mental retardation

$$
\text { Cerebral palsy }
$$

Control
TABle 5: Continued.

\begin{tabular}{lcc}
\hline Variable & $r$ value & $P$ value \\
\hline $\begin{array}{l}\text { The lateral ventricles width versus } \\
\text { epilepsy }\end{array}$ & & \\
Cerebral palsy & 0.088 & NS \\
Control & 0.579 & \\
\hline
\end{tabular}

$r$ : Spearman rank sum correlation coefficient; NS: not significant; $\wedge$ : not tested for controls.

periventricular white matter of the immature brain. The MRI features of PVL include a reduced quantity of periventricular white matter, periventricular gliosis, and ventriculomegaly with an irregular outline of the lateral ventricles $[4,16,17,24]$. In the present study, nearly $41 \%$ of patients with cerebral palsy were born prematurely and had typical PVL, and PVL (42\%) was the dominant lesion in MRI findings. Furthermore, in the conventional MRI, cortical-subcortical lesions were seen in $9.7 \%$ of patients. Meanwhile, in the volumetric MRI, significantly reduced grey matter volume was found in children with cerebral palsy compared with controls. Such results suggest that subtle structural injuries, supposedly related to motor dysfunction, may exist in these children [14]. In the present study, normal MRI findings were found only in patients with spastic diplegia.

The conventional understanding has maintained that cerebral white matter in the premature brain is especially vulnerable to hypoxia-ischemia with relative sparing of the grey matter and that grey matter injuries dominate overwhelmingly in older infants, children, and adults [25]. However, quantitative volumetric MRI studies of premature infants have demonstrated reduced volumes of the cerebral cortex [26], thalamus, basal ganglia [27], and hippocampus [28].

In a neuropathological study of premature infants, Pierson et al. [22] found that grey matter lesions occurred in at least a third of PVL cases, suggesting that white matter injuries generally do not occur in isolation and that the term perinatal panencephalopathy may better describe the scope of such neuropathology. Yin et al. [29] have reported subcortical lesions and cortical atrophy in infants born at or after 3536 weeks of gestation. In the current study, such changes occurred in $9.7 \%$ of patients, all of whom were born at term.

Grey matter injuries such as neuronal degeneration, gliosis, and subplate neuronal damage are known to be commonly associated with PVL following prenatal hypoxicischemic insult $[21,30]$. These neuronal injuries reduce regional volume, and neuronal damage occurs close to the predilection sites of white matter injury, involving predominantly the posterior brain region [30]. Our study found that the volumes of the total brain and cerebellum, as well as the widths of the lateral and third ventricles, differed significantly between children with cerebral palsy and controls. Furthermore, $41 \%$ of these children were born prematurely. The enlarged lateral and third ventricles are thought to be due to subcortical tissue loss associated with prematurity [28].

Cerebral ventricular enlargement occurs in numerous conditions, including normal aging, traumatic brain injury, and hypoxia, and has been suggested to predict neuronal 
TABLE 6: Correlations between the third-ventricle widths of brain and age, gender, gestational age, Apgar score, birth weight, GMFCS, motor and speech development, mental retardation, and epilepsy in children with cerebral palsy $(n=82)$ and controls $(n=90)$.

\begin{tabular}{|c|c|c|}
\hline Variable & $r$ value & $P$ value \\
\hline \multicolumn{3}{|c|}{ Third-ventricle width versus age } \\
\hline Cerebral palsy & -0.106 & \multirow{2}{*}{ NS } \\
\hline Control & 0.177 & \\
\hline \multicolumn{3}{|c|}{ Third-ventricle width versus male sex } \\
\hline Cerebral palsy & 0.049 & \\
\hline Control & -0.003 & NS \\
\hline \multicolumn{3}{|c|}{ Third-ventricle width versus female sex } \\
\hline Cerebral palsy & -0.004 & \\
\hline Control & 0.003 & NS \\
\hline \multicolumn{3}{|c|}{ Third-ventricle width versus gestational age } \\
\hline Cerebral palsy & -0.046 & \\
\hline Control & -0.055 & NS \\
\hline \multicolumn{3}{|c|}{ Third-ventricle width versus Apgar score } \\
\hline Cerebral palsy & -0.021 & \\
\hline Control & 0.126 & NS \\
\hline \multicolumn{3}{|c|}{ Third-ventricle width versus birth weight } \\
\hline Cerebral palsy & -0.077 & \\
\hline Control & -0.090 & NS \\
\hline \multicolumn{3}{|c|}{ Third-ventricle width versus GMFCS } \\
\hline Cerebral palsy & 0.178 & 0.088 \\
\hline Control & $\wedge$ & \\
\hline \multicolumn{3}{|c|}{ Third-ventricle width versus sitting } \\
\hline Cerebral palsy & -0.066 & \\
\hline Control & -0.136 & NS \\
\hline \multicolumn{3}{|c|}{ Third-ventricle width versus standing } \\
\hline Cerebral palsy & -0.191 & \\
\hline Control & -0.088 & NS \\
\hline \multicolumn{3}{|c|}{ Third-ventricle width versus walking } \\
\hline Cerebral palsy & -0.198 & \\
\hline Control & -0.148 & NS \\
\hline \multicolumn{3}{|c|}{ Third-ventricle width versus speech development } \\
\hline Cerebral palsy & -0.378 & \multirow{2}{*}{0.0002} \\
\hline Control & -0.094 & \\
\hline \multicolumn{3}{|c|}{ Third-ventricle width versus mental retardation } \\
\hline Cerebral palsy & 0.221 & \multirow{2}{*}{0.0334} \\
\hline Control & 0.177 & \\
\hline \multicolumn{3}{|c|}{ Third-ventricle width versus epilepsy } \\
\hline Cerebral palsy & 0.199 & \multirow{2}{*}{ NS } \\
\hline Control & -0.003 & \\
\hline
\end{tabular}

$r$ : Spearman rank sum correlation coefficient; NS: not significant; $\wedge$ : not tested for controls.

loss [31]. In our study, ventricular enlargement appeared in patients with cerebral palsy and was correlated with mental retardation and delayed speech development. Our results are in agreement with those of Lowe et al. [32], in which negative correlations between the lateral ventricles and frontal and hippocampal volumes were reported in preterm infants.
A ventricular-brain ratio exceeding 0.35 is a sensitive measure of developmental impairment (8.34). In the present study, a significant difference emerged in the Evans index between children with cerebral palsy $(0.34 \pm 0.23)$ and the controls $(0.27 \pm 0.21)$.

Numata et al. [31] investigated the association between MRI patterns and motor function, epileptic episodes, and mental development in patients born at term with spastic diplegia. MRI included normal findings (41.9\%), PVL, hypomyelination, and porencephaly or periventricular venous infarction. Moreover, the frequency of patients at GMFCS levels III-V and with intellectual disability did not differ between patients with normal and abnormal MRI findings. Patients with normal MRI findings had significantly fewer epileptic episodes than those with abnormal ones. In a systematic review, Arnfield et al. [33] reported a relationship between the type of brain lesion on MRI and gross motor function in children with cerebral palsy. These results are consistent with the findings of the present study.

An association with preterm birth or low birth weight has been found in several specific types of defects of the central nervous system, including anencephaly, hydrocephaly, microcephaly, encephalocele, spina bifida, microphthalmia, and cleft lip or palate [34].

Brain malformations originating from intrauterine maldevelopment may underlie neurologic impairment seen in children with cerebral palsy, who have a greater incidence of congenital brain malformations $[9,35,36]$. It is estimated that roughly $10 \%$ of children with cerebral palsy have different brain malformations. In the present study, we found congenital brain malformations (e.g., corpus callosum agenesis, schizencephaly, lissencephaly, and pachygyria) in $7.6 \%$ of the sample.

The MRI findings may help us to understand not only the type of lesion but also the timing of insult. The early detection of brain abnormalities in children with cerebral palsy may help in their prognosis and in the introduction of appropriate therapies (physical therapy or language therapy).

Limitations. Our population was heterogeneous in regard to the type of cerebral palsy. Second, this is a retrospective study. Third, we analyzed MRI scans with a low resolution. Replication studies within specific age groups and/or larger sample sizes and better MRI resolution will be important for establishing the generalizability of the present findings.

\section{Conclusion}

By using the voxel-based morphometry, the total brain, cerebellum, and grey matter volumes were significantly reduced in children with cerebral palsy. The grey matter volume reductions in the cerebral palsy patients suggest neuronal degeneration and damage. And ventricular enlargement was found to be significantly correlated with motor dysfunction and both speech and mental retardation in these patients. Our findings offer a deeper insight into the pathophysiological mechanisms of cerebral palsy. The voxel-based morphometry of brain in children with cerebral palsy may help in prognosis 
and in the introduction of rehabilitation of motor impairment or speech and language therapy.

\section{Competing Interests}

The authors declare that they have no competing interests.

\section{Authors' Contributions}

Piotr Kułak, Elżbieta Maciorkowska, and Elżbieta Gościk contributed equally to this work.

\section{Acknowledgments}

The authors thank AnalyzeDirect Inc., Overland Park, KS, USA, for freely using the Analyze 11 software.

\section{References}

[1] A. H. Hoon Jr., K. M. Belsito, and L. M. Nagae-Poetscher, "Neuroimaging in spasticity and movement disorders," Journal of Child Neurology, vol. 18, supplement 1, pp. S25-S39, 2003.

[2] J. Accardo, H. Kammann, and A. H. Hoon Jr., "Neuroimaging in cerebral palsy," Journal of Pediatrics, vol. 145, no. 2, pp. S19-S27, 2004.

[3] L. S. Bakketeig, "Only a minor part of cerebral palsy cases begin in labour," The British Medical Journal, vol. 319, no. 7216, pp. 1016-1017, 1999.

[4] K. L. Kwong, Y. C. Wong, C. M. Fong, S. N. Wong, and K. T. So, "Magnetic resonance imaging in 122 children with spastic cerebral palsy," Pediatric Neurology, vol. 31, no. 3, pp. 172-176, 2004.

[5] M. Staudt, "Imaging cerebral palsy," Handbook of Clinical Neurology, vol. 111, pp. 177-181, 2013.

[6] E. Garne, H. Dolk, I. Krägeloh-Mann, S. Holst Ravn, and C. Cans, "Cerebral palsy and congenital malformations," European Journal of Paediatric Neurology, vol. 12, no. 2, pp. 82-88, 2008.

[7] J. A. Pinto-Martin, S. Riolo, A. Cnaan, C. Holzman, M. W. Susser, and N. Paneth, "Cranial ultrasound prediction of disabling and nondisabling cerebral palsy at age two in a low birth weight population," Pediatrics, vol. 95, no. 2, pp. 249-254, 1995.

[8] J. Maunu, L. Lehtonen, H. Lapinleimu et al., "Ventricular dilatation in relation to outcome at 2 years of age in very preterm infants: a prospective Finnish cohort study," Developmental Medicine and Child Neurology, vol. 53, no. 1, pp. 48-54, 2011.

[9] S. Ashwal, B. S. Russman, P. A. Blasco et al., "Practice parameter: diagnostic assessment of the child with cerebral palsy: report of the Quality Standards Subcommittee of the American Academy of Neurology and the Practice Committee of the Child Neurology Society," Neurology, vol. 62, no. 6, pp. 851-863, 2004.

[10] M. N. Robinson, L. J. Peake, M. R. Ditchfield, S. M. Reid, A. Lanigan, and D. S. Reddihough, "Magnetic resonance imaging findings in a population-based cohort of children with cerebral palsy," Developmental Medicine and Child Neurology, vol. 51, no. 1, pp. 39-45, 2009.

[11] Z. Wang, X. Guo, Z. Qi, L. Yao, and K. Li, "Whole-brain voxelbased morphometry of white matter in mild cognitive impairment," European Journal of Radiology, vol. 75, no. 2, pp. 129133, 2010.

[12] D.-W. Rha, W. H. Chang, J. Kim, E. G. Sim, and E. S. Park, "Comparing quantitative tractography metrics of motor and sensory pathways in children with periventricular leukomalacia and different levels of gross motor function," Neuroradiology, vol. 54, no. 6, pp. 615-621, 2012.

[13] J. D. Lee, H.-J. Park, E. S. Park et al., "Motor pathway injury in patients with periventricular leucomalacia and spastic diplegia," Brain, vol. 134, no. 4, pp. 1199-1210, 2011.

[14] X. Mu, B. Nie, H. Wang et al., "Spatial patterns of whole brain grey and white matter injury in patients with occult spastic diplegic cerebral palsy," PLoS ONE, vol. 9, no. 6, Article ID e100451, 2014.

[15] E. R. Melhem, A. H. Hoon Jr., J. T. Ferrucci Jr. et al., "Periventricular leukomalacia: relationship between lateral ventricular volume on brain MR images and severity of cognitive and motor impairment," Radiology, vol. 214, no. 1, pp. 199-204, 2000.

[16] G. Serdaroglu, H. Tekgul, O. Kitis, E. Serdaroglu, and S. Gökben, "Correlative value of magnetic resonance imaging for neurodevelopmental outcome in periventricular leukomalacia," Developmental Medicine and Child Neurology, vol. 46, no. 11, pp. 733739, 2004.

[17] L. J. Woodward, P. J. Anderson, N. C. Austin, K. Howard, and T. E. Inder, "Neonatal MRI to predict neurodevelopmental outcomes in preterm infants," The New England Journal of Medicine, vol. 355, no. 7, pp. 685-694, 2006.

[18] S. M. Scheck, K. Pannek, S. Fiori, R. N. Boyd, and S. E. Rose, "Quantitative comparison of cortical and deep grey matter in pathological subtypes of unilateral cerebral palsy," Developmental Medicine \& Child Neurology, vol. 56, no. 10, pp. 968-975, 2014.

[19] R. Palisano, P. Rosenbaum, S. Walter, D. Russell, E. Wood, and B. Galuppi, "Development and reliability of a system to classify gross motor function in children with cerebral palsy," Developmental Medicine and Child Neurology, vol. 39, no. 4, pp. 214-223, 1997.

[20] J. Acosta-Cabronero, G. B. Williams, J. M. S. Pereira, G. Pengas, and P. J. Nestor, "The impact of skull-stripping and radiofrequency bias correction on grey-matter segmentation for voxel-based morphometry," NeuroImage, vol. 39, no. 4, pp. 1654-1665, 2008.

[21] M. Bax, M. Goldstein, P. Rosenbaun et al., "Proposed definition and classification of cerebral palsy, April 2005," Developmental Medicine and Child Neurology, vol. 47, no. 8, pp. 571-576, 2005.

[22] C. R. Pierson, R. D. Folkerth, S. S. Billiards et al., "Gray matter injury associated with periventricular leukomalacia in the premature infant," Acta Neuropathologica, vol. 114, no. 6, pp. 619-631, 2007.

[23] A. Leviton and P. Gressens, "Neuronal damage accompanies perinatal white-matter damage," Trends in Neurosciences, vol. 30, no. 9, pp. 473-478, 2007.

[24] S. M. Reid, C. D. Dagia, M. R. Ditchfield, J. B. Carlin, and D. S. Reddihough, "Population-based studies of brain imaging patterns in cerebral palsy," Developmental Medicine and Child Neurology, vol. 56, no. 3, pp. 222-232, 2014.

[25] H. C. Kinney, R. L. Haynes, and R. D. Folkerth, "White matter lesions in the perinatal period," in Developmental Neuropathology, J. A. Golden, Ed., p. 386, ISN Neuropathology Press, Basel, Switzerland, 2004.

[26] B. S. Peterson, B. Vohr, L. H. Staib et al., "Regional brain volume abnormalities and long-term cognitive outcome in preterm infants," The Journal of the American Medical Association, vol. 284, no. 15, pp. 1939-1947, 2000. 
[27] T. E. Inder, S. K. Warfield, H. Wang, P. S. Hüppi, and J. J. Volpe, "Abnormal cerebral structure is present at term in premature infants," Pediatrics, vol. 115, no. 2, pp. 286-294, 2005.

[28] C. Nosarti, M. H. S. Al-Asady, S. Frangou, A. L. Stewart, L. Rifkin, and R. M. Murray, "Adolescents who were born very preterm have decreased brain volumes," Brain, vol. 125, no. 7, pp. 1616-1623, 2002.

[29] R. Yin, D. S. Reddihough, M. R. Ditchfield, and K. J. Collins, "Magnetic resonance imaging findings in cerebral palsy," Journal of Paediatrics and Child Health, vol. 36, no. 2, pp. 139-144, 2000.

[30] I. Krageloh-Mann, D. Petersen, G. Hagberg, B. Vollmer, B. Hagberg, and R. Michaelis, "Bilateral spastic cerebral palsyMRI pathology and origin. Analysis from a representative series of 56 cases," Developmental Medicine and Child Neurology, vol. 37, no. 5, pp. 379-397, 1995.

[31] Y. Numata, A. Onuma, Y. Kobayashi et al., "Brain magnetic resonance imaging and motor and intellectual functioning in 86 patients born at term with spastic diplegia," Developmental Medicine and Child Neurology, vol. 55, no. 2, pp. 167-172, 2013.

[32] J. R. Lowe, P. C. MacLean, A. Caprihan et al., "Comparison of cerebral volume in children aged 18-22 and 36-47 months born preterm and term," Journal of Child Neurology, vol. 27, no. 2, pp. 172-177, 2012.

[33] E. Arnfield, A. Guzzetta, and R. Boyd, "Relationship between brain structure on magnetic resonance imaging and motor outcomes in children with cerebral palsy: a systematic review," Research in Developmental Disabilities, vol. 34, no. 7, pp. 22342250, 2013.

[34] W. R. Brown, "Association of preterm birth with brain malformations," Pediatric Research, vol. 65, no. 6, pp. 642-646, 2009.

[35] P. O. D. Pharoah, "Prevalence and pathogenesis of congenital anomalies in cerebral palsy," Archives of Disease in Childhood: Fetal and Neonatal Edition, vol. 92, no. 6, pp. F489-F493, 2007.

[36] J. Rankin, C. Cans, E. Garne et al., "Congenital anomalies in children with cerebral palsy: a population-based record linkage study," Developmental Medicine and Child Neurology, vol. 52, no. 4, pp. 345-351, 2010 


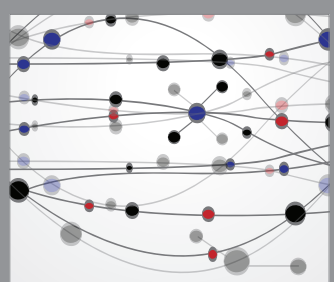

The Scientific World Journal
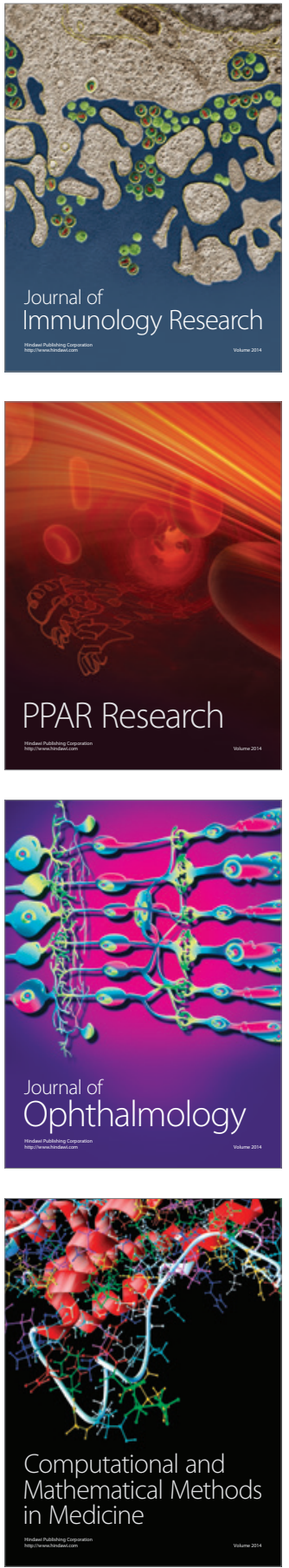

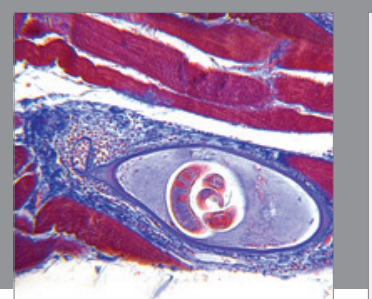

Gastroenterology Research and Practice

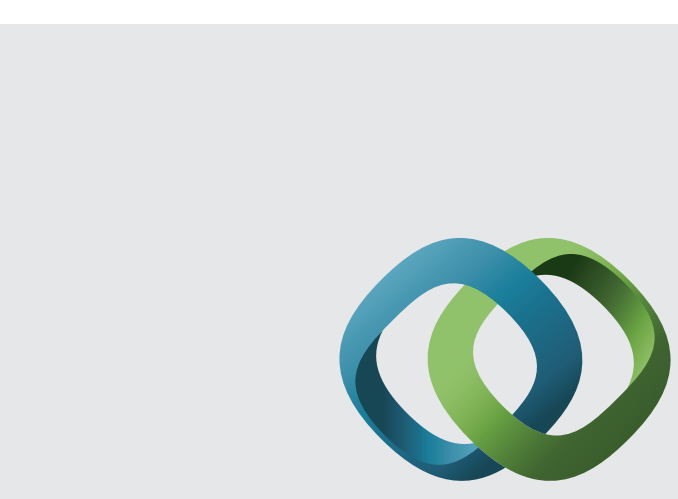

\section{Hindawi}

Submit your manuscripts at

http://www.hindawi.com
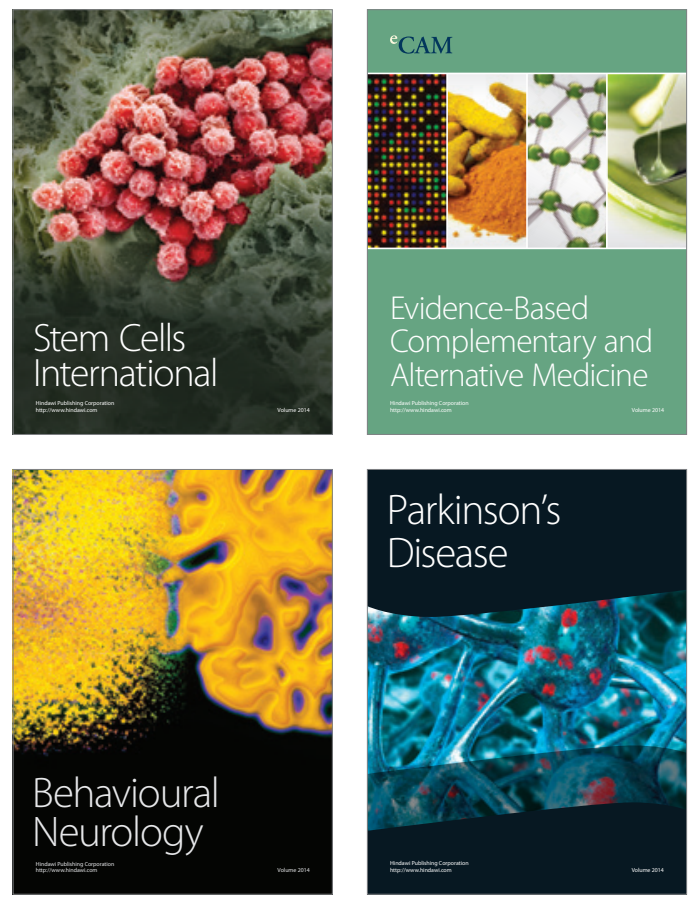
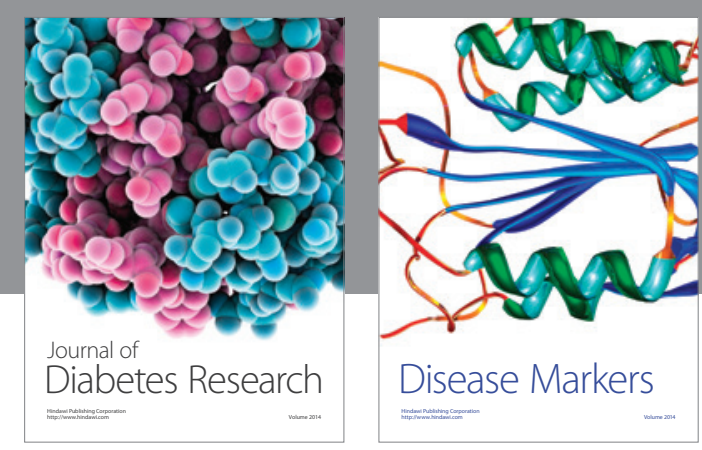

Disease Markers
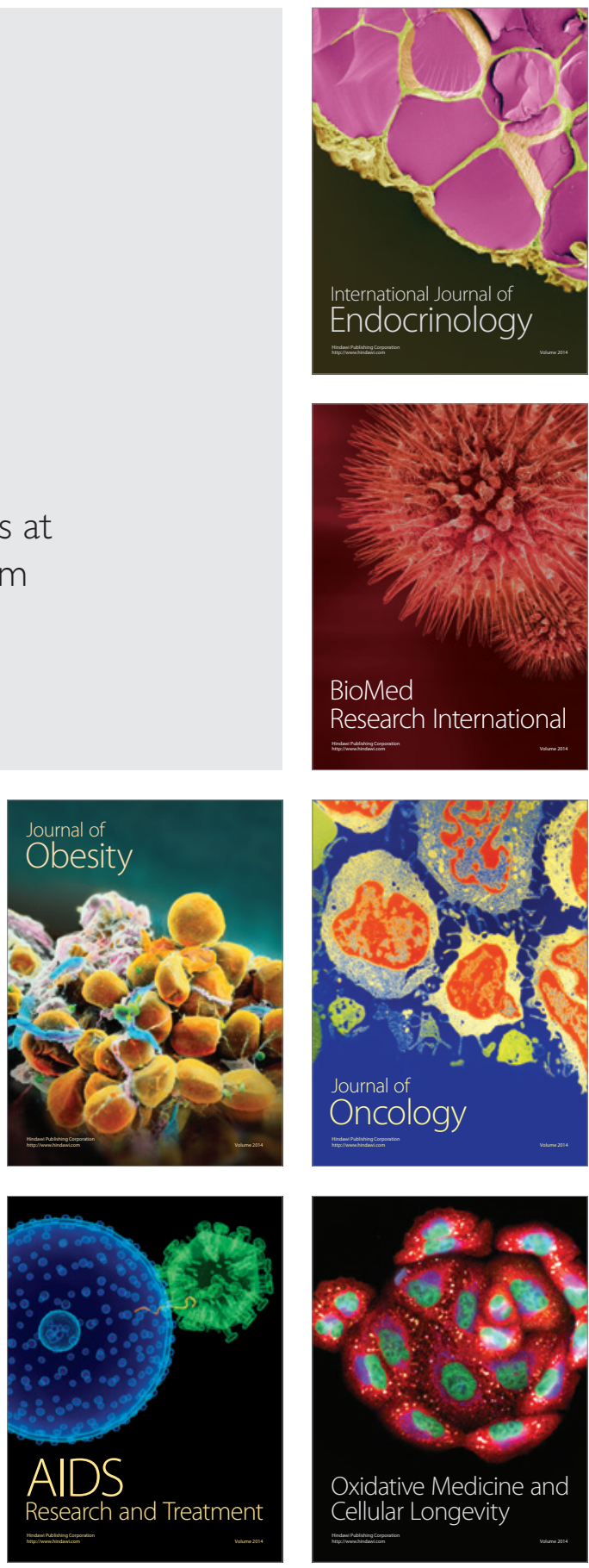